\title{
Captioned Instructional Video: Effects on Content Comprehension, Vocabulary Acquisition and Language Proficiency
}

\author{
Madhubala BavaHarji ${ }^{1}$, Zhinoos Kamal Alavi ${ }^{1} \&$ Krishnaveni Letchumanan $^{1}$ \\ ${ }^{1}$ Learning Institute for Empowerment (LiFE), Multimedia University, Malaysia \\ Correspondence: Krishnaveni Letchumanan, (LiFE), Multimedia University, FCM Building 3rd Floor, Persiaran \\ Multimedia, 63100 Cyberjaya, Selangor Darul Ehsan, Malaysia. Tel: 603-8312-5757. E-mail: \\ knaveni@mmu.edu.my
}

Received: January 24, 2014 Accepted: February 26, 2014 Online Published: April 14, 2014

doi:10.5539/elt.v7n5p1 URL: http://dx.doi.org/10.5539/elt.v7n5p1

\begin{abstract}
This experimental design study examined the effects of viewing captioned instructional videos on EFL learners' content comprehension, vocabulary acquisition and language proficiency. It also examined the participants' perception of viewing the captioned instructional videos. The 92 EFL students in two classes, who were undertaking the Tape and Video Interpretation course, participated in this study. The randomly assigned experimental class viewed 30 episodes of captioned Connect with English and the control class viewed the same episodes without captions. Adopting the quantitative approach, a Michigan English Test, Content-Specific Tests and a questionnaire were administered to examine the participants' content comprehension, vocabulary acquisition and language proficiency development as well as the experimental group's perception towards viewing captioned instructional videos. Although, both groups recorded gains, the findings were in favor of the use of captioned instructional videos. The results showed that the effects of viewing captioned instructional videos are greater on vocabulary acquisition and language proficiency development than on content comprehension. The participants' perceptions of the use of captioned instructional video were consistent with the results. They felt that it enhanced their language learning, but did not affect their comprehension of the movie and that captions were not a form of distraction. Pedagogical implications for EFL instructions, especially where multimedia technology tools may be limited is that, captioned instructional videos can be deemed as a promising media to enhance language learning.
\end{abstract}

Keywords: captioned instructional video, content comprehension, vocabulary acquisition, English Language proficiency development, EFL learners

\section{Introduction}

English Language is neither an official language in Iran nor considered a fundamentalskill to be taught in schools in Iran. With the Iranian government's move to support the national language, exposure to the language beyond the classroom is also limited and the public media is urged to broadcast translated versions of foreign movies. As Eslami-Rasekh and Valizadeh (2004) explained, only limited English programs are broadcasted on TV, radio or any other forms of media. In addition, albeit advancements in multimedia technologies, most language laboratories at the universities are equipped with conventional teaching and learning tools, such as radios, VCRs and headphones. If internet is available, its access is mostly limited and/or its speed is rather slow, which minimizes its useand hence, videos are commonly used as a teaching and learning tool. However, its potential to develop language proficiency is not fully harnessed. Baltova (1994, p. 33) explained that captioned films "provide simultaneous exposure to spoken language, printed text and visual information, all conveying the same message, and so promote content and vocabulary learning even in relatively inexperienced learners". In the same vein, Koskinen et al. (1993, p. 36) asserted that captioned video, which presents the combination of the video actions with spoken dialogues and printed words, is a powerful tool and a "promising approach for improving students' reading comprehension, vocabulary and motivation". Despite favourable findings on the effects of captioned videos (Canning-Wilson, 2000; Hinkin, 2009; Winke et al., 2010; Hwang \& Huang, 2011), both language learners and teachers appeared apprehensive. Danan (2004, p. 67) highlighted that language learners were often initially annoyed when they were first exposed to captioned programs. Language teachers too were reluctant and viewed captions as distracting. They believed that captions encouraged learners to "rely mainly on 
the written texts, taking attention away from the actual spoken language, and fostered a form of laziness bordering on cheating". Taylor (2005) concurred that learners felt that captions were distracting. Similar apprehension was also found among the Iranian language instructors, who were interviewed prior to the commencement of the study. Most of them were not in favour of the use of captions and therefore, not surprisingly, made no particularly attempt to switch the captions on when the instructional videos were screened. They were asking students to understand the conversations in the target language while they viewed the videos without captions.

\subsection{Literature Review}

With the incorporation of multimedia technology in teaching and learning, learners are exposed to different stimuli through various channels, such as verbal, visual, auditory, physical etc. Multiple-channel theory, which involves at least two input information channels, propounds that comprehension increases as learners interact with any combination of the different available sensory channels (Hsia, 1971). Paivio (1971), in his proposed dual coding theory, highlighted that information can be simultaneously represented by pictures as well as words, and these two information sources activate two coding systems: visual and verbal codes that are functionally autonomous and interconnected. Studies (Graza, 1991; Zanon, 2006; Etemadi, 2012; Winke et al., 2010) in the use to different channel sources have found that it is more probable to activate both coding systems in processing information than words or pictures alone. Koskinen et al. (1993, p. 39) highlighted that "captioned television provides a presentation of information that included opportunities to view the video action, hear the spoken word, and see the printed text". Zanon (2006, p. 43) elaborated that "a subtitled video provides a triple connection between image, sound in one language and text ... this type of connection generally encourages strong associations for retention and language ... their combination here is necessarily very powerful”. Baggett and Ehrenfeucht (1983) asserted that when students are presented with both visual and verbal/auditory input, information encoding in one medium does not hamper the other.

When captioned technology first appeared in the 1990s, educators and researchers (Holobow et al., 1984; Koskinen et al., 1993; Vanderplank, 1993; Koskinen et al., 1996) quickly saw the potentials of captioned videos, which allow for the audio-visual-print interactions to enhance multi-sensory processing, i.e. to enable students' to process language effectively in both the visual and printed forms. Captioned TV programs and videos were reported to aid the hearing impaired (Nugent, 1983), the disabled (Wilson \& Koskinen, 1986) as well as ESL/EFL learners (Garza, 1991; Markham \& Peter, 2003). Second language (L2) researchers highlighted the significance of L1 and L2 captions in developing specific language skills: listening (Garza, 1991; Markham, 1989; Huang \& Eskey, 2000; Markham \& Peter, 2003; Hayati \& Mohmedi, 2009), content comprehension (Holobow et al., 1984; Grignon et al., 2005; Grgurvoic \& Hegelheimer, 2007; Etemadi, 2012), reading comprehension (Garza, 1991; Koskinen et al., 1993; Markham \& Peter, 2003; Hwang \& Huang, 2011) and vocabulary acquisition (Huffman, 1986; Neuman \& Koskinen, 1992; Koskinen et al. 1996; Koolstra \& Beentjes, 1999; Markham \& Peter, 2003; Yukel \& Tanriverdi, 2009; Stewart \& Pertusa, 2004; Etemadi, 2012) and language learning (Borras \& Lafayette, 1994; Zanon, 2006). We will present brief descriptions of some of the related research below.

Yukel and Tanriverdi's (2009) examined the effects of captioned movies on incidental vocabulary learning, on 120 intermediate universitylevel EFL Turkish students, who viewed a closed-captioned episode of a TV series, Seinfeld. Adopting the pre-test-post-test experimental and control group design, they were randomly assigned to two groups: Group A watched the captioned movie clip and Group B watched the movie clip without caption. The students watched the first 9 minutes and 14 seconds of the movie clip twice. A 20 items Vocabulary Knowledge Scales (VKS) was administered twice; prior to (two weeks before treatment) and after the treatment (one month after treatment). Although Group A performing slightly better than Group B, the improvement was not statistically significant. Winke et al. (2010) examined the effects of captioning during video-based listening activities, which involved 150 second and fourth year Arabic, Chinese, Spanish and Russian EFL learners in a U.S university. They watched a series of three, approximately 3-5 minutes English language documentaries videos about animals, twice, i.e. once with captions and the other without captions. The screening was alternately presented, first with captions and the second without captions to all the cohorts, except the Spanish cohort (as there were two extra groups). One Spanish cohort viewed the video without captions and the other with captions. At the end of the second viewing, the students sat for two tests: i.e. content comprehension and vocabulary tests. Viewing captioned videos with aural input was found to be more effective as significantly higher scores were recorded on both tests. Winke et al. (2010) highlighted that captioned, rather than non-captioned videos aid novel vocabulary acquisition and overall comprehension of the videos, which is facilitated by the use of different modalities. They also found that the order of viewing affects recognition of vocabulary; the students who viewed 
the captioned videos first were better able to aurally recognize novel vocabulary than those who were presented with captioned videos in the second viewing.

More pertinent to this study, in terms of the language focus (comprehension/vocabulary), target group (EFL undergraduates), context of study (Iran) and instruments (standardized battery/CST/researcher designed tests) used to gather data are studies by Hwang and Huang (2011), Zarei (2009) and Etemadi (2012). Hwang and Huang (2011) examined if captioned instructional videos improve or impede Taiwanese EFL learners' reading comprehension. 80 college freshmen were randomly assigned to the experimental and control groups. The experimental group viewed the captioned videos and the control group viewed the non-captioned videos to for one hour every two weeks over 10 weeks (a period of 5 weeks). Two instruments were used to gather data: (i) a Content Comprehension Test (CST), which was designed by the researchers to assess the participants' comprehension (listening and content) and vocabulary acquisition of only the $50^{\text {th }}$ episode. (ii) General English Proficiency (GET), a standardized test that the Taiwan Ministry of Education designed to assess students' overall language proficiency, in terms of listening and reading skills. The descriptive statistics of the reading comprehension sub-test of the GET showed that the experimental group out-performed the control group, however, the statistical analysis showed no significant differences between the mean reading scores.

Zarei's (2009) conducted a study to examine the effects of bimodal, standard and reversed subtitling on L2 learners' vocabulary recognition and recall. The participants of this study were made up of 92 BA level Iranian students ( 3 groups), who viewed nine episodes (30 minutes per episode) of a British TV comedy at the last half an hour of each class session (which was an additional task in the regular class activities and materials). All groups viewed the same film. The first group viewed the film with both the English soundtrack and subtitles, the second group viewed the film with English soundtrack and Persian subtitles, and the third group viewed the film with Persian soundtrack and English subtitles. They were also required to view the films as homework and short content comprehension quizzes were carried out to ensure they viewed the films at home. Two vocabulary tests, which the research designed, were administered as post-tests. The first vocabulary test, (40 multiple-choice questions), was administered at the end of the study, to examine the participants' comprehension of the words, that appeared in the film. The second vocabulary test (40 fill-in-the-blank questions) was administered a week after the study to measure the participants' recall of the vocabulary. A 40-item multiple-choice vocabulary sub-section of the Michigan test was also administered to gauge the homogeneity of the participants, before the study as well as a post-test to valid the post-tests that were administered at the end of the study. This study found no significant difference between the bimodal and standard subtitling groups for vocabulary recognition, however, both groups performed significantly better than the reversed subtitling group. The results of vocabulary recall, on the other hand, showed that bimodal subtitling was significantly more effective than standard subtitling, which in turn was significantly more effective than reversed subtitling.

Etemadi's (2012) one-shot case study examined the effects of bimodal captions of English movies on content comprehension and vocabulary recognition. The 44 senior Iranian undergraduates in her study watched two BBC documentaries, with and without English subtitles, in one session. The screening of the two documentaries was reversed to counteract the order effects. Class 1 viewed Dangerous knowledge with captions, followed by Where's my robot? Without captions. Class 2 viewed the same documentaries in reversed order. Immediately after viewing each of the documentaries, the participants answered a set of 20 multiple choice questions (10 questions each on vocabulary and content comprehension) per documentary. The researcher designed the two sets of tests (a total of 40 multiple choice questions: 20 questions each on vocabulary and content comprehension). The $t$-test results showed positive effects of the bimodal subtitling on content comprehension, but not on vocabulary recognition.

Koskinen et al. (1993, p. 41) asserted, "The instructional potential of captioned video is enormous". The plausible effects of captioned instructional video in enhancing Iranian EFL learners' integrated language skills, i.e. comprehension vocabulary acquisition and language proficiency was one of the motivations to carry out this study. As mentioned earlier, most of the language instructors who were interviewed prior to this study appeared apprehensive of the effectiveness of captions. Secondly, based on our google search, we found limited studies werecarried out in Iran and except for two studies (Etemadi, 2012; Zarei \& Rashvand, 2011), the rest of the studies appeared to focus on the effects of captions on isolated language skills: listening (Latifi et al., 2011; Hayati \& Mohmedi, 2009; Ghasemboland \& Nafissi, 2012) and vocabulary (Zarei, 2009; Taghavi et al., 2012). The two studies that examined integrated language skills are Zarei and Rashvand's (2011) study that focused on vocabulary and production, and Etemadi's (2012) study on content comprehension and vocabulary. Thirdly, there also appears to be limited studies that examine the effectiveness of captioned instructional video on integrated language skills. Most studies, as mentioned earlier, appeared to focus on isolated language components, i.e. listening (Kusumarasdyati, 2005; Hayati \& Mohmedi, 2009), reading and/or content 
comprehension, language learning (Borros \& Lafayette, 1994; Grignon et al., 2005; Zanon, 2006) and mostly on vocabulary (Garza, 1991; Koolstra \& Beentjes, 1999; Birds \& Willians, 2002; Stewart \& Pertusa, 2004; Hinkin, 2009).

Thus, this study had set out to, firstly, provide evidence for the use of captions in a Tape and Video Interpretation course in addressing the language instructors' apprehension, secondly, to fill in the research gap by extending previous studies and examining three integrated components, i.e. comprehension (content/reading), vocabulary acquisition and language proficiency development as well as examining the students' perceptions of viewing captioned instructional videos, and finally, to contribute to the body of literature, particularly in the EFL context, where the possibility of using advanced multimedia technologies in classrooms/language laboratories may be limited to the use of only VCRs.

\subsection{Research Questions}

This study addressed the following research questions:

1) Does the presence of English language captions in instructional videos improve EFL learners'

a) Content comprehension?

b) Vocabulary acquisition?

c) Language proficiency?

2) What are the EFL learners' perceptions of captioned instructional videos?

\section{Methodology}

\subsection{Participants}

Participants of this study were made up of all 92 (33\% male and 76\% female) EFL students undertaking the Tape and Video Interpretation course at Islamic Azad University of Mashhad, Iran. Their ages ranged from 19 to 24 years. Since two classes were held, one was randomly set as the experimental (45 students) and the other as the control (47 students) groups. To gauge the participants' level of proficiency before the treatment, a Michigan English (2009) Test (MET) was administered and the results of the pre-MET is presented in Table 1.

Table 1. Pre-MET

\begin{tabular}{lllll}
\hline Groups & $\mathrm{N}$ & Mean Scores & Std. Deviation & Std. Error Mean \\
\hline Experimental & 45 & 67.42 & 12.41 & 1.85 \\
Control & 47 & 63.10 & 12.84 & 1.87 \\
\hline
\end{tabular}

As shown in Table 1, the descriptive statistics of the results of the pre-MET confirmed that the participants in both the experimental and control groups were approximately of the same level of language proficiency; they recorded mean scores within the 60 - 70 range, with a mean difference of $<5$ (Experimental: $M=67.42$; Control: $M=63.10$ ), which implied that they were homogeneous and at the intermediate level. To verify if there was statistical difference between the groups, we ran a $t$-test for equality of means and the results, which are presented in Table 2, show that the mean difference between the two groups was not statistically significant: $t$ (90) $=-1.63, p=0.105 \geq .05$. 
Table 2. $T$-test for equality of mean for pre-MET

\begin{tabular}{|c|c|c|c|c|c|c|c|c|c|c|}
\hline \multicolumn{11}{|c|}{ Independent sample test } \\
\hline & & \multicolumn{3}{|c|}{$\begin{array}{l}\text { Levene's } \\
\text { Test for } \\
\text { Equality of } \\
\text { Variances }\end{array}$} & \multicolumn{6}{|c|}{ T-test for Equality of Mean } \\
\hline & & \multirow[t]{2}{*}{$\mathrm{F}$} & \multirow[t]{2}{*}{ Sig. } & \multirow[t]{2}{*}{$\mathrm{T}$} & \multirow[t]{2}{*}{ Df } & \multirow[t]{2}{*}{$\begin{array}{c}\text { Sig. } \\
\text { (2-tailed) }\end{array}$} & \multirow[t]{2}{*}{$\begin{array}{c}\text { Mean } \\
\text { Difference }\end{array}$} & \multirow[t]{2}{*}{$\begin{array}{l}\text { Std Error } \\
\text { Difference }\end{array}$} & $\begin{array}{r}95 \% \mathrm{Co} \\
\text { Interva } \\
\text { Diffe }\end{array}$ & $\begin{array}{l}\text { fidence } \\
\text { of the } \\
\text { ence }\end{array}$ \\
\hline & & & & & & & & & Lower & Upper \\
\hline \multirow{2}{*}{$\begin{array}{l}\text { Pre- } \\
\text { MET }\end{array}$} & $\begin{array}{l}\text { Equal } \\
\text { Variances } \\
\text { assumed }\end{array}$ & .071 & .791 & -1.63 & 90 & .105 & -4.31 & 2.63 & -9.55 & .92 \\
\hline & $\begin{array}{l}\text { Equal } \\
\text { Variances } \\
\text { not assumed }\end{array}$ & & & -1.63 & 89.99 & .105 & -4.31 & 2.63 & -9.55 & .91 \\
\hline
\end{tabular}

Hence, it is possible to contend that any change in the experimental group's mean scores, at the end of the treatment, would be deemed as the presence of English language captions in instructional videos improves EFL learners' language proficiency.

\subsection{Materials}

An instructional video series, Connect with English (McGraw-Hill, 1998) was used in this study. Connect with English (CWE) is a soap opera about a journey of a young aspiring singer, Rebecca Casey, who leaves Boston to pursue her dreams in the music in California. The complete CWE series comprises 25 videos, with 50 fifteen-minute episodes (including the Introduction and Meet with Discussion Group). Every two 15 minute episodes are on a specific theme. McPartland-Fairman et al. (1998) noted that the language levels of each episode pursue a sequence. The vocabulary in the earlier episodes is simpler compared to the later episodes, which is more advanced. They elaborated that the "key lines are repeated, important events are retold and idioms are paraphrased...there are constant visual clues, such as notes, documents, written signs, facial expressions, gestures and body language to convey meaning".

Upon confirming that the 92 participants have not viewed the video prior to the study, both groups were briefed on the story leading up to the events relating to the $18^{\text {th }}$ episode (Intermediate level). The decision to begin the treatment with episode 18 was based on the results of the pre-MET, which showed that the participants were at the intermediate level as well as the description of the levels of the episodes in the Teacher's Guide of the instructional video. The experimental group watched $C W E$ with captions and the control group watched the same video without captions.

\subsection{Instruments}

Adopting the inferential statistic procedure, this study gathered quantitative data, using the MET, the Content Specific Tests (CST) and a questionnaire to address the research questions. The MET and CST were used to gather data to answer the first research question (Does the presence of English language captions in the instructional video improve EFL learners' content comprehension, vocabulary acquisition and English language proficiency?). Thea questionnaire was used to gather data on to answer the second research question (What are the EFL learners' perceptions of captioned instructional video?).

\subsection{Michigan English Test (MET)}

Briefly, the MET is for adults and adolescents at or above a secondary level of education non-native speakers of English, who will need to use English for academic purposes at the college and university level (University of Michigan, 2010). It is used to evaluate English language proficiency in different contexts, including education. It constitutes five sub-sections: reading comprehension (three reading passages, 25 multiple choice questions to be completed in 35 minutes), listening comprehension ( 25 multiple choice questions, to be completed in 20 minutes), vocabulary and grammar (25 multiple choice items each, to be completed in 15 minutes for each component), and writing (this sub-section was not administered for two reasons, firstly, as the manual specifies, 
it is recommended to be administered when trained raters are available to assess the scripts and secondly, it was not the focus of this study). The scoring of MET followed the manual guidelines, i.e. each item was scored "1" for a correct answer and " 0 " for an incorrect answer. Since the MET comprised 100 multiple choice questions, the possible maximum score was 100 marks. Hence, we deemed that the total scores attained reflected the improvement in the participants' language proficiency.

The Michigan English 2009 Test Administration Report published by the University of Michigan's English Language Institute Testing and Certification Division reported very high reliability, i.e. between 0.90 and 0.93 (University of Michigan, 2010) for all sub-sections of the MET. Winster et al. (2009) too reported a reliability of $\mathrm{r}=0.75$. A sample of the questions is attached as Appendix A.

\subsection{Content Specific Tests (CST)}

The CST, which the Testing Centre of the English Department of Islamic Azad University developed, was designed based on the major concepts and information presented in the video. The tests were adopted to examine the participants' content comprehension as well as vocabulary acquisition. Each content specific test comprised eight questions (four questions on content comprehension and another four questions on vocabulary sections) on one theme, the complete set of CST (15 sets of tests) was made up of 120 multiple choice questions (60 questions for each of the content comprehension and vocabulary sections). The duration for each test was eight minutes (4 minutes for each section). Similar to the MET, correct responses were awarded "1" point and incorrect responses were scored as zero, and the maximum possible score was 120 marks. The total scores for the 15 tests were tallied to record the participants' final scores. A sample of the CST question is attached as Appendix B.

To ensure content validity, three experienced (more than 10 years of teaching experience) EFL instructors, who viewed the video prior to the commencement of the study, reviewed the test items. A five-point Likert-scale was adopted: (1) Very Appropriate, (2) Appropriate, (3) Fair, (4) Inappropriate, and (5) Very Inappropriate. Items rated below the scale of 2 were revised as proposed by the instructors and a coordination meeting was held with the instructors to verify the 120 multiple choice questions.

\subsection{Questionnaire}

The researchers designed a questionnaire to examine the experimental group's perceptions of captioned instructional videos as well as to triangulate data. It comprised six statements: four statements that required responses of strongly disagree to strongly agree (using the 5 Likert scale) and two statements, which required a "yes - no" response (See Appendix C). Of the six statements, two statements (statement 4 in section A: "When I read the words in the captions, I miss the story line." and statement 1 in section B: "I have a better understanding of the movie when I read the subtitles.") were aimed at collecting data on the participants' perception of the effects of viewing captioned instructional movie on content comprehension. The remaining three statements in section A (My Knowledge of new words increased with the help of captions, I understand the meaning of words better with the help of the actions in the instructional videos, I tend to remember the new words that I come across in the captions) were aimed at gathering feedback on the participants' perception of the effects of viewing captioned instructional video on vocabulary acquisition. Statement 2 in section B (I learn English better with subtitled instructional videos) was aimed at eliciting their perception on whether captioned instructional video is an effective tool for learning English. The same three EFL instructors, who validated the CST, verified the face validity of the questionnaire.

\subsection{Data Collection}

Table 3. Data collection schedule

\begin{tabular}{|c|c|c|c|c|c|c|c|}
\hline & $\begin{array}{l}\text { Data } \\
\text { Collection }\end{array}$ & & & & & & Data Collection \\
\hline Weeks & \multirow{3}{*}{ Pre-MET } & 1 & 2 & 3 & 4 & 5 & \multirow{3}{*}{$\begin{array}{l}\text { - Post-MET } \\
\text { Questionnaire }\end{array}$} \\
\hline${ }^{\mathrm{a}}$ Class Sessions & & $\begin{array}{lll}1 & 2 & 3 \\
\end{array}$ & $\begin{array}{lll}4 & 5 & 6 \\
\end{array}$ & $\begin{array}{lll}7 & 8 & 9 \\
\end{array}$ & $\begin{array}{lll}10 & 11 & 12 \\
\end{array}$ & $\begin{array}{lll}13 & 14 & 15 \\
\end{array}$ & \\
\hline Episode Numbers & & $18-23$ & $24-29$ & $30-35$ & $36-41$ & $42-47$ & \\
\hline
\end{tabular}

${ }^{\mathrm{a}}$ Content-Specific Tests were administered at the end of each class session 
Table 3 displays the schedule for treatment and the administration of the instruments. It was conducted over a five week period, with three sessions per week, which totaled 15 sessions. The participants viewed two episodes for 90 minutes per class session, beginning with episode 18 and ending with episode 47; they viewed a total of 30 episodes ( 15 themes).

In week 1, the participants viewed episodes 18 to 23 ( 2 episodes per week), i.e. 18-19 in session 1, 20-21 in session 2 and 22-23 in session 3. In week 2, another three class sessions (4 to 6) were held and the participants viewed another three episodes (24 to 29). This goes on for weeks 3 (episode 30-35), 4 (episode (36-41) and 5 (episode 42-47). The MET was administered twice, i.e. as a pre-test and post-test to gauge the participants' language proficiency before and after the treatment respectively. Since one CST was administered at the end of each class session, the participants sat for 15 content specific tests, which were aimed at examining the participants' content comprehension and vocabulary acquisition. The third instrument was administered at the end of final treatment to elicit their perception of the use of the captioned instructional video.

\section{Results}

The results of the data analysis of the MET and CST, using the SPSS software version 16, are presented as descriptive statistics. The $t$-test equality of means, which was conducted to verify the variance of the mean scores of both the results are also presented to support the findings. The level of significance was set at 0.05 . Responses to the questionnaire are tabulated as percentages.

The results presented below are in response to the research questions, which are reiterated here for ease of reference:

1) Does the presence of English language captions in instructional video improve EFL learners'

a) Content comprehension?

b) Vocabulary acquisition?

c) Language proficiency?

2) What are the EFL learners' perceptions of captioned instructional videos?

\subsection{Content Comprehension and Vocabulary Acquisition}

In addressing parts (a) and (b) of the first research question, this section presents the results of the CST on content comprehension and vocabulary acquisition. Table 4 presents the descriptive statistics of the CST computed scores for both the sub-sections.

Table 4. Descriptive statistics of sub-sections of Content Specific Tests

\begin{tabular}{|c|c|c|c|c|}
\hline \multirow[b]{2}{*}{ Groups } & \multicolumn{2}{|c|}{ Mean Scores (Standard Deviations) } & \multicolumn{2}{|l|}{ Std. Error Mean } \\
\hline & $\begin{array}{l}\text { Content } \\
\text { Comprehension }\end{array}$ & Vocabulary & $\begin{array}{l}\text { Content } \\
\text { Comprehension }\end{array}$ & Vocabulary \\
\hline Experimental & $46.00(8.09)$ & $46.20(9.38)$ & 1.207 & 1.39 \\
\hline Control & $44.64(8.58)$ & $31.79(13.98)$ & 1.253 & 2.04 \\
\hline
\end{tabular}

The results clearly show that the experimental group performed better than the control group in both sub-sections. The experimental group recorded slightly higher mean scores, i.e. $\geq 46$ (for both sub-sections) than the control group's mean scores of $\leq 45$. The experimental group recorded mean scores that were almost similar, with a .20 variant for both sub-sections (Content Comprehension, $M=46.00$; Vocabulary, $M=46.20$ ). In contrast, the control group recorded more varied mean scores; they performed better in content comprehension $(M=44.64)$ than in vocabulary $(M=31.79)$. A similar pattern is seen in the standard deviations of both the groups. A more varied standard deviation was found for the control group in both sub-sections (Content Comprehension, $S D=$ 8.58; Vocabulary, $S D=13.98$ ) than the experimental group (Content Comprehension, $S D=8.09$; Vocabulary, $S D=9.38$ ). In comparing the performance in each of the sub-sections separately, the difference between the means scores and standard deviations for the content comprehension section was not obvious, i.e. $M D=1.36$ points (Experimental, $M=46.00$; Control, $M=44.64$ ) and a difference of .49 in $S D$ (Experimental, $S D=8.09$; Control, $S D=8.58$ ) respectively. On the contrary, there was a wider mean difference of 14.41 , in favour of the experiment group for the vocabulary section (Experimental, $M=46.20$; Control, $M=31.79$, but the variance in scores within the experimental group $(S D=9.38)$ was smaller compared to the control group $(S D=13.98)$. To 
verify the results, we ran the $t$-test to examine if there was any statistical difference between the groups. The results showed that there was no significant difference for content comprehension $(t(90)=-.73, p=.436)$, indicating that the experimental group did not out-perform the control group. However, the wider difference in mean scores between the groups for vocabulary was significant, $t(90)=-5.78, p=.000$ (See Table 5).

Table 5. $T$-test for equality of means for Content Specific Tests

\begin{tabular}{|c|c|c|c|c|c|c|c|c|}
\hline & & \multirow[t]{2}{*}{$\mathrm{T}$} & \multirow[t]{2}{*}{ df } & \multirow[t]{2}{*}{$\begin{array}{c}\text { Sig. } \\
\text { (2-tailed) }\end{array}$} & \multirow[t]{2}{*}{$\begin{array}{c}\text { Mean } \\
\text { Difference }\end{array}$} & \multirow[t]{2}{*}{$\begin{array}{l}\text { Std. Error } \\
\text { Difference }\end{array}$} & \multicolumn{2}{|c|}{$\begin{array}{l}95 \% \text { Confidence } \\
\text { Interval of the } \\
\text { Difference }\end{array}$} \\
\hline & & & & & & & Upper & Lower \\
\hline \multirow{2}{*}{ Content } & $\begin{array}{l}\text { Equal Variances } \\
\text { assumed }\end{array}$ & -.728 & 90 & .436 & -1.362 & 1.742 & -4.822 & 2.099 \\
\hline & $\begin{array}{l}\text { Equal Variances } \\
\text { not assumed }\end{array}$ & -.783 & 89.980 & .436 & -1.362 & 1.740 & -4.818 & 2.094 \\
\hline \multirow{2}{*}{ Vocabulary } & $\begin{array}{l}\text { Equal Variances } \\
\text { assumed }\end{array}$ & -5.779 & 90 & .000 & -14.413 & 2.494 & -19.367 & -9.458 \\
\hline & $\begin{array}{l}\text { Equal Variances } \\
\text { not assumed }\end{array}$ & -5.827 & 80.774 & .000 & -14.413 & 2.473 & -19.334 & -9.491 \\
\hline
\end{tabular}

\subsection{Language Proficiency}

As mentioned earlier, in addressing the research question "Does the presence of English language captions in instructional videos improve EFL learners' language proficiency? " The MET was re-administrated at the end of the treatment to examine if there was improvement in language proficiency. The descriptive statistics of the preand post-MET are displayed in Table 6 for ease of comparison.

Table 6. Descriptive statistics of pre- and post-MET

\begin{tabular}{llllllll}
\hline \multirow{2}{*}{ Groups } & \multirow{2}{*}{$\mathrm{N}$} & \multicolumn{2}{l}{ Mean Scores } & \multicolumn{2}{c}{ Std. Deviation } & \multicolumn{2}{l}{ Std. Error Mean } \\
\cline { 3 - 8 } & & Pre-MET & Post-MET & Pre-MET & Post-MET & Pre-MET & Post-MET \\
\hline Experimental & 45 & 67.42 & 82.88 & 12.41 & 5.94 & 1.85 & 0.88 \\
Control & 47 & 63.10 & 68.12 & 12.84 & 13.06 & 1.87 & 1.90 \\
\hline
\end{tabular}

The descriptive statistics in Table 6 shows that both groups benefited from viewing the captioned instructional video. As mentioned earlier, before the treatment, both groups were approximately of the same level of language proficiency, i.e. at the intermediate level (Experimental, $M=67.42, S D=12.41$; Control, $M=63.10, S D=$ 12.84), however, after the treatment, although positive effects of viewing the instructional videos were evident for both groups, the experimental groups' performance was much better than the control group. The level of language proficiency of the experimental group improved to the advanced level, i.e. with means scores of $>80$ $(M=82.88)$ compared to the control group, who remained at the intermediately level $(<70 ; M=68.12)$, but recorded higher means scores in the post-test than the pre-test $(M=I 63.10)$. When the mean scores between the pre- and post-tests for each group are compared, the experimental group recorded an obvious increase of 15.46 (pre-MET: $M=67.42$; post-MET: $M=82.88$ ) compared to the control group, who recorded an increase of only 5.02 (pre-MET: $M=63.10$; post-MET: $M=68.12$ ). As for the variance in scores within the groups, the standard deviations between the groups in the post-test was smaller for the experimental group $(S D=5.94)$ than the control group $(S D=13.06)$. The experimental group clearly out-performed the control group, with a wider mean difference, i.e. $M D=14.76$ (Experimental, $M=82.88$; Control, $M=68.12$ ) in the post-test. The mean difference in the pre-test, however, wassmaller, i.e. $M D=4.32$ (Experimental, $M=67.42$; Control, $M=63.10$ ). Once again, we ran a $t$-test to examine if the differences in mean scores were statistically significant (See Table 8). 
Since this study examined the effects of viewing the instructional video on content comprehension and vocabulary acquisition (Research Question 1), we analyzed the participants' performance in the individual reading comprehension and vocabulary sub-sections of the post-MET further (See Table 7).

Table 7. Descriptive statistics of reading comprehension and vocabulary of post-MET

\begin{tabular}{llllll}
\hline Group Statistics & & & & & \\
\hline \multirow{2}{*}{ Reading Comprehension } & Group & $\mathrm{N}$ & Mean & Std. Deviation & Std. Error Mean \\
& Experimental & 45 & 18.53 & 3.49 & 0.52 \\
& Control & 47 & 16.65 & 3.75 & 0.54 \\
\hline \multirow{2}{*}{ Vocabulary } & Experimental & 45 & 19.13 & 3.18 & 0.47 \\
& Control & 47 & 17.04 & 3.53 & 0.51 \\
\hline Reading Comprehension \& & Experimental & 45 & 37.66 & 6.31 & 0.94 \\
Vocabulary & Control & 47 & 33.70 & 6.88 & 1.00 \\
\hline
\end{tabular}

As shown in the table, there was only a slight difference in performance between the groups, in favour of the experimental group. Although the mean difference between the groups for the reading comprehension section was < 2, i.e. 1.88 (Experimental, $M=18.53$; Control: $M=16.65$ ), a slightly wider mean difference of $>2$, i.e. 2.09, in favor of the experimental group for the vocabulary sections (Experimental, $M=19.13$; Control: $M=$ 17.04) was recorded. With the slight difference in performance in the individual sub-sections, we decided to analysis the results further by combining the scores of both the sub-sections to draw a more reliable conclusion. We found a wider difference of 3.96 (Experimental, $M=37.66$; Control, $M=33.70$ ) when the scores of both sub-sections were combined. Similar to the CST, we ran at-test for the total scores attained in the post-MET, individual sub-sections for the reading comprehension and vocabulary sections as well as the combined sub-sections to examine if there were statistical differences in the mean scores. The results are presented in Table 8.

Table 8. $T$-test for equality of mean

\begin{tabular}{llllll}
\hline Group Statistics & & & & & \\
\hline \multirow{2}{*}{ Reading Comprehension } & Group & $\mathrm{N}$ & Mean & Std. Deviation & Std. Error Mean \\
\hline \multirow{2}{*}{ Vocabulary } & Experimental & 45 & 18.53 & 3.49 & 0.52 \\
& Control & 47 & 16.65 & 3.75 & 0.54 \\
\hline Reading Comprehension & Experimental & 45 & 19.13 & 3.18 & 0.47 \\
\& Vocabulary & Control & 47 & 17.04 & 3.53 & 0.51 \\
\hline & Control & 47 & 33.70 & 6.88 & 0.94 \\
\hline
\end{tabular}

The $t$-test results confirm that the experimental group performed significantly better than the control group in the overall performance of the post-MET $(t=-6.92, p=.000)$, in the individual sub-sections, i.e. reading comprehension $(t=-2.47, p=.015)$ vocabulary $(t=-2.97, p=.004)$ as well as the combined sections $(t=-2.87$, $p=.005)$.

\subsection{Perception of Captioned Instructional Video}

To recap, a questionnaire was administered to elicit the participants' perception of viewing the captioned instructional video and to triangulate data. The descriptive analysis of the sections A and B are presented in Tables 9 and 10 respectively. 
Table 9. Responses to the section A of questionnaire

\begin{tabular}{lcccccc}
\hline $\begin{array}{l}\text { Section A } \\
\text { Items }\end{array}$ & $\mathrm{N}(\%)$ & $\mathrm{FD}^{*}(\%)$ & $\mathrm{F}(\%)$ & $\mathrm{F}(\%)$ & $\mathrm{F}(\%)$ & $\mathrm{F}(\%)$ \\
\cline { 5 - 7 } $\begin{array}{l}\text { Q1 (Knowledge of new } \\
\text { words increased with the }\end{array}$ & $45(100 \%)$ & $0(0 \%)$ & $0(0 \%)$ & $0(0 \%)$ & $35(77.8 \%)$ & $10(22.2 \%)$ \\
help of captions)
\end{tabular}

* SD: Strongly Disagree; D: Disagree; NS: Not Sure; A: Agree; SA: Strongly Agree;

*F: Frequency

At a quick glance, we can that the responses varied from strongly agreeing to strongly disagreeing to three statements (Statements 2, 3, 4), except statement 1 (Knowledge of new words increased with the help of captions). All 45 participants affirmed (77.8\% Agreed, 22.2\% Strongly Agreed) that the provision of captions attributed to increase in vocabulary, however, the responses to statement 2: "I understand the meaning of words better with the help of the actions in the videos" were more varied. While 26 (57.8\%) participants agreed (35.6\% agreed, $22.2 \%$ strongly agreed) that actions in the video attributed to better understanding of the meaning of words, $10(22.2 \%)$ participants disagreed and the remaining $9(20 \%)$ participants were unsure, of the scaffolding effects of an action in the video to help decipher the meaning of the words. The third statement: "I tend to remember the new words that I come across in the caption" was intended to examine how sustainable the effects of providing captions were in terms of remembering new words. Approximately half of the participants, i.e. 23 (51.1\%) participants agreed that they tend to remember the new words in the captions, $12(28.3 \%)$ participants felt that they tend to forget the new words and $10(22.2 \%)$ participants were unsure as to whether captions were helpful. In comparison, a larger proportion of the participants, i.e. 28 (62.2\%) participants disagreed with statement 4 (When I read the words in the captions, I miss the story line). 13 (28.9\%) participants noted they were unsure and only $4(8.9 \%)$ participants felt that they missed the story line.

Responses to section B of the questionnaire, i.e. the participants' perceptions toward the effects of captions on content comprehension and language learning are presented in Table 10.

Table 10. Responses to section B of questionnaire

\begin{tabular}{llll}
\hline Section B & $\mathrm{N}(\%)$ & YES & NO \\
\hline Items & Frequency (\%) & Frequency (\%) \\
\hline $\begin{array}{l}\text { Q5 (Better understanding of the } \\
\text { movie when read the captions) }\end{array}$ & $45(100 \%)$ & $4(8.9 \%)$ & $41(91.1 \%)$ \\
$\begin{array}{l}\text { Q6 (Learn English better with } \\
\text { captioned video) }\end{array}$ & $45(100 \%)$ & $35(77.8 \%)$ & $10(22.2 \%)$ \\
\hline
\end{tabular}

In general, the number of responses recorded for both statements in Section B appears to indicate that the majority of the participants felt that captions did not attribute to enhanced understanding of the content of the video, nevertheless, favoured the captioned instructional video as a tool to learn English. While, only a small proportion of participants, i.e. $4(8.7 \%)$ perceived that they had " $\ldots$ a better understanding of the movie when [they] read the captions", a majority of participants, i.e. 41 (91.1\%) felt that captions did not enhance their comprehension of the movie. Conversely, a larger proportion of participants, i.e. 35 (77.8\%) perceived that they “... learn English better with captioned videos" and only 10 (21.7\%) participants felt otherwise. 


\section{Discussion}

This section presents the discussion on the findingsin response to the research questions, which are reiterated for ease of reference:

1) Does the presence of English language captions in instructional videos improve EFL learners'

a) Content comprehension?

b) Vocabulary acquisition?

c) Language proficiency?

2) What are the EFL learners' perceptions of captioned instructional videos?

The discussions will begin with the effects of viewing instructional captioned videos on content comprehension and vocabulary acquisition, followed by language proficiency development. The participants' perceptions towards instructional captioned videos are discussed simultaneously to triangulate data in support of the findings.

\subsection{Content Comprehension}

In reporting the effects of captions on content comprehension, we analyzed the results of the comprehension sub-section of the CST, reading comprehension section of the MET and questionnaire. The descriptive statistics and independent samples $t$-test on content comprehension (CST) clearly points to no obvious/significant difference in performance between the groups. This is consistent with the views of most of the participants in the experimental group, who felt that the printed form of the dialogues appeared to neither attribute to better understanding of the movie, nor affect their understanding of the storyline. A larger proportion of the participants felt that captions, as Koostra and Beentjes (1999) noted, are far from distracting, and this contradicts Taylor's (2005) findings that it affects comprehension of the movie. A concern for lack of familiarity may lead to a sense of distraction, as raised by Lambert and Holobow (1984), may not be the case in this study, since the participants in this study had not viewed $C W E$, which is set in the US, prior to the treatment. These results also appear to contradict Holobow et al. (1984), Grignon et al. (2005), Grgurovic and Hegelheimer (2007), and Etemadi's (2012) findings that captions have a positive effect on content comprehension. The results of the reading comprehension section of the MET, which contradicts Hwang and Huang's findings (2011), showed favourable effects of captioned instructional video. The significant difference between the groups is consistent with Garza's (1991) and Koskinen et al.'s (1993) findings.

\subsection{Vocabulary Acquisition}

Similar to content comprehension, data on vocabulary acquisition were obtained from the three instruments. Interestingly, in contrast to the findings on content comprehension, but similar to reading comprehension, the effects of viewing captioned instructional videos on vocabulary acquisition was significant. The experimental group, who was able to "hear" the dialogue and "see" the printed captions simultaneously, displayed improved vocabulary acquisition, compared to the control group. Once again, consistency was found in the test results and the participants' perception towards vocabulary acquisition. All the students participants felt that captions helped improve their vocabulary, which was reflected in their significant performance in the vocabulary sub-sections of the CST and MET. Most of the participants also felt that they understood the meanings of words better when the printed forms appeared concurrently with the actions in the video. The visual stimuli of the actions appeared to attribute to better understanding of the vocabulary. Our results, therefore, contradict Etemadi's (2012) findings that bimodal captioning did not affect vocabulary acquisition. However, our results are consistent with findings reported by Neuman and Koskinen (1992), Koskinen et al. (1993), Zarei (2009), Yuksel and Tanriverdi (2009), and Winke, Gass, and Sydorenko (2010).

In general, our findings suggest that viewing captioned instructional video has a positive effect on vocabulary acquisition, but not on content comprehension. This finding appears to contradict Etemadi's (2012) result which suggested otherwise. Her study reported the reverse effects, i.e. positive effects of captioned movies on content comprehension, but not vocabulary. However, it ought to be noted that she adopted the "one-shot" case study and ours was an experimental study, which was conducted over a 5-week period and the participants viewed a series of episodes.

\subsection{Language Proficiency}

In response to the research question, "Does the presence of English language captions in instructional videos improve EFL learners' language proficiency?" We found that viewing instructional videos, irrespective of captioned or non-captioned, enhances English language proficiency. It attests to what Koskinen et al. (1993) maintained, i.e. a promising approach for enhancing language proficiency. However, it appears to be an even 
more promising approach, if captioned videos are used as a teaching and learning tool in an EFL context. We found that captioned videos appear to have a greater effect on language proficiency than non-captioned videos. The experimental group recorded greater improvement than the control group. Recording a greater increase in mean score $(M D=15.46)$ compared to the control group $(M D=5.02)$, their level of language proficiency improved to the advanced level. The $t$-test verified the significant difference in the overall performance of the post-MET as well as the individual and combined sections of the reading comprehension and vocabulary. The participants' perception of the use of captions, i.e. that they learn English better with the aid of captions is reflected in the results. This improvement in English language proficiency is consistent with the findings by Borras and Lafayette (1994), and Zanon (2006). As Paivio (1971) highlighted, this study too found that multiple presentation of information in spoken, written and visual forms had contributed positively to increased performance and improved language proficiency than single presentation.

\section{Limitations of Study}

Several limitations are recognized and acknowledged in this paper. Among the limitations were the language components, choice of instruments and duration of study. Firstly, although this study examined integrated language skills on content comprehension, vocabulary acquisition and language proficiency, other language skills, such as listening, speaking, grammar and writing were not examined. Secondly, we used the MET, which is a standardized test battery and the CST, which were available at the university. The duration of each CST was limited to only eight minutes per test, i.e. one minute per question, which appears to be a speed test. Within the limited class time, we were unable to allocate more time. Inclusive of the questionnaire, we collected only quantitative data and therefore we were unable to report the participants' feedback beyond the statements in the questionnaire. In addition, a delayed post-test was not administered to determine if the effects of viewing captioned instructional video lasted. The third limitation was the duration of study, which entailed limited episodes were screened, i.e. over a five week period, the participants viewed only 30 of the total 50 episodes, starting with episode 18 to 47.

The results may have varied if different materials and instruments were used as well as the the time allocation for the CST and the duration of the study were longer. The use of other materials, such as documentaries, non-instructional videos, cartoons may yield a different set of results. We found that familiarity of the movie does not affect performance, however, if familiar movies or movies with the local context were used, the performance of the students may have been even better. The results may have varied if other assessment tools and standardized test battery were administered, or even if other types of questions, such as open-ended or structured questions were used, instead of multiple choice questions. The results may have also differed, if the students were given the opportunity to view the complete $C W E$ series, i.e. all 50 episodes from the beginning, rather than only 30 episodes.

\section{Recommendation for Future Research}

Suggestions for future research include examining a more integrated component of the language skills, i.e. productive (oral/written) and receptive (grammar/reading/listening) skills. Based on our literature review, a larger proportion of studies appear to examine vocabulary acquisition. There appears to be no specific study that examined the effects of captions on grammar and there is also limited study on the oral and written productive skills. Future research could examine these components in isolation or as integrated components as well as learning strategies, which are also not extensively researched. The use of non-instructional materials or even materials that the students are familiar with can also be considered in future research. A suggestion is to elicit students' feedback on the types of materials they would like to view. Screening videos of the students' choice or preference could be an additional form of motivation to enhance language learning and develop autonomous learning. Future research could also consider the number of times the materials are screened and follow up activities could be conducted to reinforce language learning. Next, we collected only quantitative data and therefore future studies could adopt a mix-method approach to include qualitative data by conducting interviews that would give a more lucid picture of their perception of the use of the materials. In addition, delayed post-test(s)/assessment tools could be administered to examine the lasting effects of viewing captioned materials.

\section{Conclusion}

To recap, the aim of this study was to examine the effects of captioned instructional video on EFL learner's content comprehension, vocabulary acquisition and language proficiency. The findings clearly point to the promising multimedia tool of captioned instructional video as an effectives approach in enhancing EFL teaching and learning. Regardless of viewing the instructional video with or without captions, the gains are evident in the integrated components examined. However, it is also evident that the gains are significant when captions are used and the participants' perception of the use of captioned instructional video was consistent with the results. They felt that it 
enhanced their language learning, but did not affect their comprehension of the movie and that captions were not a form of distraction. Hence, this study supports the view that exposure to bimodal input via multi-channels results in better performance than exposure to only a single channel. We can conclude that the combination of visual, audio and print media attributes positively to language proficiency and extend Koskinen et al. (1993)'s view that captioned video is not only "a promising approach for improving student's reading comprehension and vocabulary", but also content comprehension and language proficiency.

Pedagogical implications of this study are, firstly the findings of this study provides evidence for the use of captions/multi-channel media to enhance EFL learners' language proficiency, which helps dispel EFL language instructors' apprehension of making conscious use of captions as a teaching/learning tool. Secondly, in ESL/EFL contexts, where incorporating innovative multimedia technology tools into the language classrooms are restrained due to various factors/constraints/may be limited to the use of the basic multimedia tool of the VCR, captioned instructional videos can be deemed as promising media.

\section{References}

Baggett, P., \& Ehrenfeucht, A. (1983). Encoding and retaining information in the visuals and verbals of an instructional movies. Instructional Communication and Technology, 31(1), 23-32.

Baltova, I. (1994). The impact of video on comprehension skills of core French students. Canadian Modern Language Review, 50, 507-531.

Birds, S. A., \& Willians, J. (2002). The effect of bimodal input on implicit and explicit memory: An investigation into the benefits of within language subtitling. http://dx.doi.org/10.1017/S0142716402004022

Borras, L., \& Lafayette, R. (1994). Effects of multimedia courseware subtitling on the speaking performance of college students of French. The Modern Language Journal, 78, 61-75. http://dx.doi.org/10.1111/j.1540-4781.1994.tb02015.x

Canning-Wilson, C. (2000). Practical aspects of using video in the foreign language classroom. The Internet TESL Journal, 6, 11. Retrieved from http://iteslj.org/Articles/Canning-Video.html

Danan, M. (2004). Captioning and subtitling: Undervalued language learning strategies. Meta, 49(1), 67-77. http://dx.doi.org/ 10.7202/009021ar

Eslami-Rasekh, Z., \& Valizadeh, K. (2004). Classroom activities viewed from different perspectives: Learners' voice vs. teachers' voice. TESL EJ, 8(3), 1-13. Retrieved from http:// testl-ej.org/ej31/a2.html

Etemadi, A. (2012). Effects of bimodal subtitling of English movies on content comprehension and vocabulary recognition. International Journal of English Linguistics, 2(1), 239-248. http://dx.doi.org/10.5539/ijel.v2n1p239

Garza, T. (1991). Evaluating the use of captioned video materials in advanced foreign language learning. Foreign Language Annals, 24(3), 239-258. http://dx.doi.org/10.1111/j.1944-9720.1991.tb00469.x

Ghasemboland, F., \& Nafissi, Z. (2012). The effects of using English captions on Iranian EFL students' listening comprehension. http://dx.doi.org/10.1016/j.sbspro.2012.11.013

Grignon, P., Lavaur, J. M., \& Blanc, N. (2005). The effects of subtitles on film understanding. Retrieved from http://sites.google.com/site/jeanmarchlavaur/grigronlavaurblacn2007.pdf

Grgurovic, M., \& Hegelheimer, V. (2007). Help options and mutimedia listening: Students' use of subtitles and the transcript. Language Learning \& Technology, 11(1). Retrieved from http://IIt.msu.edu/vol1 1num1/pdf/grgurovic.pdf

Hayati, M., \& Mohmedi, F. (2009). The effects of films with and without subtitles on listening comprehension of EFL learners. British Journal of Educational Technology. http://dx.doi.org/10.1111/j.167-8535.2009.01004.x

Hinkin, M. (2009). Comprehension of multiple channel messages: Are subtitles more beneficial than soundtracks? Retrieved from http://krex.kstate.edu/dspace/bitstream/2097/1679/1/MichaelHinkin2009.pdf

Holobow, N., Lambert, W., \& Sayegh, L. (1984). Pairing script and dialogue: combinations that show promise for second or foreign language learning. Language Learning, 34(4), 59-76. http://dx.doi.org/10.1111/j.1467-1770.1984.tb00352.x

Hsia, J. (1971). The information capacity of modality and channel performance. Audio Visual Communication Review, 19(1), 51-75. http://dx.doi.org/10.1007/BF02768431

Huang, H., \& Eskey, D. (2000). The effects of closed-captioned televison on the listening comprehnsion of 
intermediate English as a second lanague students. Educational Technology Systems, 28, 75-96.

Huffman, D. (1986). Soap operas and captioning in the ESL class. Paper presented at the International Conference Language Teaching and Learning, Japan.

Hwang, Y., \& Huang, P. (2011). Using subtitles to enliven reading. English Language and literature studies, l(1). http://dx.doi.org/10.5539/ells.v1n1p2

Koolstra, C., \& Beentjes, W. (1999). Children's vocabulary acquisition in a foreign language through watching subtitled television at home. Educational Technology, Research and Development, 47, 51-60. http://dx.doi.org/10.1007/BF02299476

Koskinen, P., Wilson, R., Gambrell, L., \& Neuman, S. (1993). Captioned video and vocabulary learning: An innovative practice in literacy instruction. The Reading Teacher, 47(1), 36-43.

Koskinen, P., Knable, J., Markam, P., Jensema, C., \& Kane, K. (1996). Captioned television and the vocabulary acquisition of adult second language correctional facility residents. Journal of Educational Technology Systems, 24, 359-373. http://dx.doi.org/10.2190/JKC2-LE5D-36BC-809F

Kusumarasdyati. (2005). Subtitled movie DVDs in FL classes. Monash University. Retrieved from http://www.raare.edu.au/kus06105.pdf

Latifi, M. M., \& Mohammadi, E. A. (2011). Movie subtitles and the improvement of listening comprehension ability: Does it help? The Journal of Language Teaching and Learning, 1(2), 18-29.

Lambert, W. E., \& Holobow, N. E. (1984). Combinations of printed script and spoken dialogues that show promise for beginning students of a foreign language. Canadian Journal of Behavioural Science, 16, 1-11. http://dx.doi.org/10.1037/H0080775

Markham, P. L. (1989). The effects of captioned television on the listening comprehension of beginning, intermediate, and advanced ESL students. Instructional Technology, 29(10), 38-41.

Markham, P., \& Peter, L. (2003). The influence of English language and Spanish language captions on foreign language listening/reading comprehension. Journal of Educational Technology Systems, 31(3), 331-341.

McPartland-Fairman, P., Berman, M., Butler, L., \& Sokolik, M. (1998). Connect with English: Video Comprehension Books, 1, 2, 3, \& 4. New York: McGraw-Hill.

Neuman, S. B., \& Koskinen, P. (1992). Captioned television as comprehensible input: Effects of incidental word learning from context for language minority students. Reading Research Quarterly, 27(1), 94-106. http://dx.doi.org/10.2307/747835

Nugent, G. (1983). Deaf students' learning from captioned instruction: The relationship between the visual and caption display. The Journal of Special Education, 17, 227-234. http://dx.doi.org/10.1177/00224669830170021

Paivio, A. (1971). Imagery and cognitive process. New York: Holt, Rinehart.

Stewart, M., \& Pertusa, I. (2004). Gains to language learners from viewing target language closed-captioned films. Foreign Language Annals, 37(3), 434-447. http://dx.doi.org//10.1111/j.1944-9720.2004.tb02701.x

Taghavi, M., Sabet, M. K., \& Zafarghandi, A. M. (2012). The effects of captioned brief news on Iranian secondary students' vocabulary learning. International Journal of Scientific and Engineering Research, $3(11)$.

Taylor, G. (2005). Perceived processing strategies of students watching captioned video. Foreign Language Annals, 38(3), 422-427. http://dx.doi.org/10.1111/j.1944-9720.2005.tb02228.x

University of Michigan, English Language Institute. (n.d.). Retrieved from: http://www.lsa.umich.edu/eli/testing

Yuksel, D.. \& Tanriverdi, B. (2009). Effects of watching captioned movie clip on vocabulary development of EFL learner. TOJET, 8(2).

Vanderplank, R. (1993). A very verbal medium: Language learning through closed captions. TESOL Journal, $3(1), 10-14$.

Wilson, R., \& Koskinen, P. (1986). Closed-captioned television. The Exceptional Parent, 16, 46-47.

Winke, P., Gass, S. M., \& Sydorenko, T. (2010). The effects of captioning videos used for foreign language listening activities. Language Learning \& Technology, 14(1), 65-86. Retrieved from http://llt.msu.edu/vol14num1/winkegasssydorenko.pdf 
Zanon, N. T. (2006). Using subtitles to enhance foreign language learning. Porta Linguarum, 6. Retrieved from http://www.ugr.es/ portalin/articulos/PL_numero6/talavan.pdf

Zarei, A. A. (2009). The Effect of bimodal, standard, and reversed subtitling on L2 vocabulary recognition and recall. Special Issue, English, 49, 65-85.

Zarei, A. A., \& Rashvand, Z. (2011). The effects of interlingual and intralingual, verbatim and nonverbatim subtitles on L2 vocabulary comprehension and production. Journal of Language Teaching and Research, 2(3), 618-625. http://dx.doi.org/10.4304/jltr.2.3.618-625

\section{Appendices}

Appendix A: Sample of Test Questions in MET

\begin{tabular}{|c|c|c|c|}
\hline Sections & No of questions & Example of Questions & Allocated Time \\
\hline Listening & 25 & $\begin{array}{l}\text { a. She reads more slowly than the man does. } \\
\text { b. She has a lot of material to read before she has coffee. } \\
\text { c. The man does more work than is necessary. } \\
\text { d. The man seems to be taking a long time preparing for } \\
\text { philosophy class. }\end{array}$ & 20 minutes \\
\hline $\begin{array}{l}\text { Reading } \\
\text { Comprehension }\end{array}$ & 25 & $\begin{array}{l}\text { What does the passage mainly discuss? } \\
\text { a. The career of Maria Edgeworth as an author of } \\
\text { children's books } \\
\text { b. The development of children's literature in the United } \\
\text { Stales } \\
\text { c. Successful publishers of children's books in Britain and } \\
\text { North America } \\
\text { d. Basic differences between British and American } \\
\text { literature for children }\end{array}$ & 35 minutes \\
\hline Vocabulary & 25 & $\begin{array}{l}\text { Politicians should not___ from the laws they pass. } \\
\text { a. earn } \\
\text { b. profit } \\
\text { c. increase } \\
\text { d. finance }\end{array}$ & 15 minutes \\
\hline
\end{tabular}

The "confederation school" poets of nineteenth-century Canada were primarily nature poets, eulogies to Canadian rural life.

$\begin{array}{ll}\text { Grammar } 25 & \text { a. and producing } \\ & \text { b. who they produced } \\ & \text { c. producing } \\ & \text { d. whose production of }\end{array}$

\begin{tabular}{lll}
\hline Total & 100 & 85 minutes
\end{tabular}


Appendix B: Samples of test items from episode 18 in CST

\begin{tabular}{|c|c|c|c|}
\hline Section & No. of Questions & Question & Time \\
\hline Vocabulary & 4 & $\begin{array}{l}\text { Your pictures are quite __ They are so strange. } \\
\text { a. Striking } \\
\text { b. Special } \\
\text { c. Familiar } \\
\text { d. Small }\end{array}$ & 4 minutes \\
\hline $\begin{array}{l}\text { Content } \\
\text { Comprehension }\end{array}$ & 4 & $\begin{array}{l}\text { Have Rebecca and Diana met before? } \\
\text { a. Yes } \\
\text { b. No } \\
\text { c. Not mentioned in the video }\end{array}$ & 4 minutes \\
\hline $\begin{array}{l}\text { Total questions per } \\
\text { class session }\end{array}$ & 8 & & 8 minutes \\
\hline $\begin{array}{l}\text { Total questions at the } \\
\text { end of the treatment } \mathrm{t}^{\mathrm{a}}\end{array}$ & 120 & & 105 minutes \\
\hline
\end{tabular}

${ }^{\mathrm{a}} 60$ content comprehension and 60 vocabulary questions

Appendix C: Questionnaire

\begin{tabular}{llllll}
\hline Section A & $\mathbf{S D}^{\mathrm{a}}$ & $\mathbf{D}^{\mathrm{b}}$ & $\mathbf{N S}^{\mathrm{c}}$ & $\mathbf{A}^{\mathrm{d}}$ & $\mathbf{S A}^{\mathrm{e}}$ \\
\hline 1.
\end{tabular}

1. My knowledge of new words increased with the help of captions.

2. I understand the meaning of words better with the help of the actions in the videos.

3. I tend to remember the new words that I come across in the captions.

4. When I read the words in the captions, I miss the story line.

\begin{tabular}{lll}
\hline$S D^{\mathrm{a}}:$ Strongly Disagree, $D^{b}:$ Disagree, $N S^{c}:$ Not Sure, $A^{d}:$ Agree, $S A^{e}:$ Strongly Agree & \\
\hline Section B & YES & NO
\end{tabular}

1. I have a better understanding of the movie when I read the captions.

2. I learn English better with captioned videos.

\section{Copyrights}

Copyright for this article is retained by the author(s), with first publication rights granted to the journal.

This is an open-access article distributed under the terms and conditions of the Creative Commons Attribution license (http://creativecommons.org/licenses/by/3.0/). 